\title{
Vincent Lemire (sous la direction de) avec Katell Berthelot, Julien Loiseau et Yann Potin, Jérusalem. Histoire d'une ville-monde
}

Danielle Delmaire

\section{(2) OpenEdition Journals \\ Édition électronique \\ URL : https://journals.openedition.org/tsafon/425 \\ DOI : $10.4000 /$ tsafon.425 \\ ISSN : 2609-6420 \\ Éditeur \\ Association Jean-Marie Delmaire}

\section{Édition imprimée}

Date de publication : 1 décembre 2017

Pagination : 163-165

ISSN : 1149-6630

\section{Référence électronique}

Danielle Delmaire, «Vincent Lemire (sous la direction de) avec Katell Berthelot, Julien Loiseau et Yann Potin, Jérusalem. Histoire d'une ville-monde », Tsafon [En ligne], 74 | 2017, mis en ligne le 31 mai 2018, consulté le 02 juillet 2021. URL : http://journals.openedition.org/tsafon/425 ; DOI : https://doi.org/ $10.4000 /$ tsafon. 425

Ce document a été généré automatiquement le 2 juillet 2021.

Tsafon. Revues d'études juives du Nord 


\title{
Vincent Lemire (sous la direction de) avec Katell Berthelot, Julien Loiseau et Yann Potin, Jérusalem. Histoire d'une ville-monde
}

\author{
Danielle Delmaire
}

\section{RÉFÉRENCE}

Vincent Lemire (sous la direction de) avec Katell Berthelot, Julien Loiseau et Yann Potin, Jérusalem. Histoire d'une ville-monde, Paris, Flammarion, coll. Champs Histoire, octobre 2016, 535 p., $12 €$.

1 Quatre auteurs, chacun spécialiste d'une période historique: Antiquité, Moyen Âge, époques moderne et contemporaine se sont associés pour rédiger les sept chapitres de cet ouvrage copieux. Commençons par deux petites remarques négatives avant de développer un commentaire plus positif. Prétendre, dans l'introduction, qu'il n'existe aucune histoire de Jérusalem des origines jusqu'à nos jours, c'est jeter aux oubliettes au moins un ouvrage qui certes est moins fouillé et débute son histoire avec le roi David, celui de Renée Neher : Jérusalem, trois millénaires d'histoire, du roi David à nos jours, paru en 1997. Par ailleurs, il est dommage que les chapitres ne soient pas signés même si l'on peut deviner, lorsque l'on connaît les collaborateurs de Vincent Lemire, qui a pu les écrire. Ce sont-là des défauts mineurs au regard de la somme érudite mais très accessible au grand public que représente ce livre dont la publication est soutenue par le centre national du livre et le CNRS.

2 Le projet était ambitieux mais le résultat est impressionnant. L'introduction évoque une «ville écrasée de mémoires, fourbue d'identités " et affirme "Jérusalem ne s'appartient pas, Jérusalem n'est pas à Jérusalem, Jérusalem est une ville-monde », une ville qui interpelle le monde entier. Avec justesse, les auteurs ont pris le parti d'une 
histoire chronologique et non thématique. Sur une telle étendue temporelle, c'est l'option la plus sage! Les premières traces d'occupation remontent à 4000 av. n. è. soit 6000 ans d'histoire. Encore fallait-il décrire la topographie du lieu constitué de collines forgées par des vallées parfois profondes, avec plus de $200 \mathrm{~m}$ de dénivelé, agitées de temps à autre par des tremblements de terre, situées dans un milieu relativement sec et entourées d'une végétation méditerranéenne bien peu luxuriante, même si le climat a pu connaître quelques modifications au cours de ces six millénaires. L'occupation humaine a d'ailleurs bougé dès l'Antiquité : du flanc des collines, la ville s'est hissée vers les sommets pour se cantonner durant de longs siècles dans l'actuelle vieille ville puis s'étaler sur plusieurs dizaines de $\mathrm{km}^{2}$ durant le siècle dernier.

3 À son apparition, la « ville-monde " n'est qu'un très modeste village à l'écart des routes mais proche de sources indispensables pour une vie sédentaire. Les fouilles trahissent une occupation discontinue durant les deux premiers millénaires au moins. Jérusalem est longtemps une petite ville soumise à ses voisins, notamment la puissante Égypte dès le XIve siècle av. n. è. La période du roi David n'est pas aussi magnifique que le dit la Bible et son royaume fut probablement bien modeste, les travaux des archéologues israéliens revoyant à la baisse la puissance du roi David sont désormais reconnus, malgré les trouvailles archéologiques de Tel Dan (au nord) et de la stèle du roi de Moab, Mesha. Il n'empêche que la ville de David a laissé des traces sur le flanc de la colline de l'Ophel, non loin des sources. Ce n'est, en fait, qu'après la prise de Samarie et la disparition du royaume du Nord que Jérusalem se développe. Avec Ézéchias, un canal souterrain alimente la ville et une inscription retrace son creusement, et c'est alors que la littérature biblique s'extasie sur la magnificence de Jérusalem ou Sion (Psaumes notamment) qui devient emblématique de l'identité des Hébreux.

4 Avec la défaite de 586 av. n. è., Jérusalem ne sera plus qu'une ville de province, toujours sous domination étrangère jusqu'à l'établissement de l'État actuel d'Israël. L'époque perse a permis le "retour à Sion » mais la ville reste modeste, se cantonnant dans un rôle religieux autour du Temple. C'est avec les Grecs qu'elle recouvre un certain lustre avec les constructions, somptueuses pour certaines (embellissement du Temple), entreprises par Hérode. Une partie de la population se laisse gagner par l'hellénisation ce qui provoque des tensions avec les juifs les plus religieux. La Jérusalem traversée par Jésus est alors sous le pouvoir de Rome qui finit par mater ses opposants irréductibles quelques décennies plus tard. L'imposant Temple est détruit, Jérusalem va disparaître pour devenir Aelia Capitolina.

5 Après cette déroute des juifs, dès que le christianisme est autorisé dans l'Empire de Constantin, le christianisme s'empare de la ville et la marque par la construction de nombreuses églises dont la plus connue est, évidemment, le Saint-Sépulcre. Les pèlerins viennent nombreux sur les traces de Jésus, de Marie, des apôtres. Le judaïsme qui l'avait consacrée s'efface.

6 Cette partie sur l'Antiquité que l'on doit probablement à Katell Berthelot est très bien exposée et documentée: toutes les disciplines (archéologie, épigraphie, sources bibliques en évitant la lecture théologique, littératures des civilisations voisines) sont convoquées pour rétablir, autant que possible, ce passé de 4000 ans.

$7 \mathrm{Au}$ judaïsme et au christianisme succède l'islam, dès les débuts de l'expansion musulmane à la fin du $\mathrm{VII}^{\mathrm{e}}$ siècle. Sous les Omeyyades, Jérusalem reste un centre religieux mais à côté des églises sont construites des mosquées (dont la magnifique mosquée d'Omar) et des madrassas ouvrent. Le Haram al sharif (le noble sanctuaire) 
devient le $3^{\text {e }}$ sanctuaire de l'islam, il se superpose à l'emplacement du Temple des juifs tandis que les chrétiens restent à l'écart avec le Saint-Sépulcre. L'islam marque alors la ville pour de longs siècles sauf durant l'intermède du Royaume franc qui rechristianise violemment la ville : des mosquées sont transformées, les juifs et les musulmans sont temporairement expulsés.

8 L'intermède chrétien est de courte durée, durant la période mamelouke (fin XIII ${ }^{e}$-fin $\mathrm{xV}^{\mathrm{e}}$ siècles) puis ottomane jusqu'au début $\mathrm{du} \mathrm{xx}^{\mathrm{e}}$ siècle, l'islam retrouve sa place dominante et déchristianise partiellement la ville tandis que les juifs, sujets protégés, sont autorisés à se réinstaller. Dès lors les trois religions ont leur place sacrée : le mur occidental ou ruine du Temple d'Hérode, le Saint-Sépulcre, le Haram al Shariff. Mais bien que ville trois fois sainte, Jérusalem reste toujours une ville de province et n'est jamais instituée capitale d'un État. Les périodes mamelouke et ottomane sont propices au développement économique, des marchés s'animent (le marché des cotonniers existe toujours), des artisans s'activent. Mais durant tous ces siècles, Jérusalem demeure un lieu de pèlerinage pour les juifs et les chrétiens. À l'aube du $\mathrm{xx}^{\mathrm{e}}$ siècle, la population juive est même majoritaire.

9 Les XIX et $\mathrm{XX}^{\mathrm{e}}$ siècles transforment la ville. En Europe, le goût pour l'Orient engage des écrivains et des voyageurs à s'intéresser à Jérusalem. L'essor du millénarisme amène des chrétiens. Beaucoup, tels Chateaubriand, Loti et bien d'autres, sont déçus par sa petitesse et sa saleté. L'intérêt des puissances européennes pour la région qui appartient encore à l'Empire ottoman en pleine décadence (l'Homme malade) favorise l'implantation de consulats et de missions chrétiennes aussi diverses que nombreuses. Et même l'œuvre philanthropique de l'Alliance israélite universelle ouvre des écoles. Enfin, dans les deux dernières décennies $d u x x^{e}$ siècle, la ville commence à être touchée par la première alyah, l'immigration des pionniers juifs. Sous influence européenne, la ville sort des remparts qui l'étouffent et se modernise : une gare de chemin de fer est construite hors les murs, une horloge publique donne un autre rythme au temps, l'éclairage favorise les déambulations nocturnes.

Dès la veille de la Première Guerre mondiale, Jérusalem devient le lieu de concurrence entre les deux nationalismes, sioniste et arabe, qui s'exacerbent au fil des années de l'entre-deux-guerres. Vite, la Grande-Bretagne, la puissance mandataire qui remplace l'Empire ottoman déchu par sa défaite, échoue dans la maîtrise des populations.

11 Jérusalem devient la capitale de l'État d'Israël mais non reconnue comme telle par les autres pays, capitale israélienne et non internationale, divisée à l'issue de la guerre de 1948-1949 entre la Jordanie qui possède la vieille ville et Israël qui développe rapidement la ville dans sa partie occidentale. Juifs et Arabes sont repoussés dans leur secteur respectif bien que la partie israélienne conserve quelques quartiers habités minoritairement par des Arabes tandis qu'aucun juif ne peut rester dans la partie jordanienne. Divisée puis réunifiée après la Guerre des Six Jours, une fois encore la ville connaît des bouleversements. Les Israéliens aménagent les alentours du mur occidental qu'ils n'avaient pas pu approcher durant 20 ans, au prix de destructions de maisons arabes, mais ils doivent aussi reconstruire tous les édifices juifs qui avaient été démolis durant la période jordanienne.

Depuis la ville ne cesse de s'agrandir de façon tentaculaire. Jérusalem l'israélienne voit défiler les touristes juifs, les pèlerins chrétiens et les curieux du monde entier. 
13 Ces chapitres consacrés aux $\mathrm{XIX}^{\mathrm{e}}$ et $\mathrm{xx}^{\mathrm{e}}$ siècles, probablement dus à Vincent Lemire, livrent une histoire équilibrée sans parti pris ce qui n'est pas toujours évident pour évoquer un passé et un présent si troublés et suscitant encore tant de passion.

14 Il faut encore apprécier les cartes qui accompagnent chacune des périodes et une chronologie, exploit ambitieux, s'étalant sur quatre millénaires et occupant 25 pages. Un livre utile aux spécialistes de l'histoire de la "ville-monde » ainsi qu'à tout lecteur intéressé par cette histoire et ils sont nombreux dans le monde. 